Research paper

\title{
A comparative study of seizures in arterial and venous stroke
}

\author{
R.K. Singh, S.K. Bhoi, Jayantee Kalita, Usha Kant Misra*, D. Gupta \\ Department of Neurology, Sanjay Gandhi Post Graduate Institute of Medical Sciences, Lucknow, India
}

A R T I C L E I N F O

\section{Article history:}

Received 28 September 2016

Accepted 11 January 2017

Available online 30 January 2017

\section{Keywords:}

Arterial stroke

CVST

Seizure

Post stroke seizure

\begin{abstract}
A B S T R A C T
Objective: This study was undertaken to compare the frequency, spectrum and predictors of seizures in arterial stroke and cerebral venous sinus thrombosis (CVST).

Methods: The patients having seizures following arterial stroke or CVST during 2010-2015 were included. Stroke was confirmed by computerized tomography (CT) scan, magnetic resonance imaging (MRI) and or MR Venography (MRV). The seizures were categorized into early seizures ( $<14$ days) and late seizures ( $\geq 14$ days) of arterial stroke or CVST. Neurological findings, risk factors for stroke and CVST were noted. The severity of stroke was defined by National Institute of Health Stroke Scale (NIHSS). The outcome on discharge was assessed by modified Rankin Scale (mRS) as good $(0-2)$ or poor $(>2)$.

Results: There were 870 patients with arterial stroke and 128 with CVST. Seizures occurred in 74 (57.8\%) of CVST and 119 (13.7\%) of arterial stroke. Early seizures were more common in CVST than arterial stroke ( $98.6 \%$ vs. $47.9 \%, p=0.001)$ whereas late seizures were more common after arterial stroke than CVST ( $52.1 \%$ vs. $1.4 \%, \mathrm{p}=0.001)$. In the arterial stroke, seizures were predicted by carotid territory ischemic stroke (OR 3.95, 95\% CI 1.51-10.32, p=0.005) and CVST by parenchymal involvement (OR 2.61, 95\% CI 1.04-6.55, $\mathrm{p}=0.04$ )

Conclusion: CVST results in more frequent and early seizures whereas in arterial stroke late seizures are common. Post stroke seizures in ischemic stroke were predicted by carotid territory infarction and venous stroke by parenchymal involvement.
\end{abstract}

๔ 2017 Published by Elsevier, a division of RELX India, Pvt. Ltd on behalf of Indian Epilepsy Society.

\section{Introduction}

Stroke is the most important cause of mortality and disability after coronary artery disease and cancer. The incidence of stroke is likely to increase with the increasing age of the population. Cerebrovascular disease is the most important cause of epilepsy in elderly population. ${ }^{1,2}$ It has been estimated that $6.9-11.5 \%$ patients with stroke were at the risk of developing post stroke seizure and the incidence of seizures increased with age. ${ }^{3-5}$ Presence of structural brain lesion, EEG abnormalities and partial seizures may have higher recurrence rate. ${ }^{6}$ Male gender and cortical location of stroke independently predicted increased risk of seizures. In India, the stroke occurs at younger age because of high incidence of

Abbreviations: CVST, cerebral venous sinus thrombosis; CT, computerized tomography; MRI, magnetic resonance imaging; MRV, MR venography; NIHSS, National Institute of Health Stroke Scale; mRS, modified rankin scale; CNS, central nervous system; TOAST, trial of ORG 1072 in acute stroke treatment; ICH, intracerebral hemorrhage; SE, status epilepticus; GCS, Glasgow coma scale; EEG, electroencephalography; ICP, intracranial pressure; MV, mechanical ventilation.

* Corresponding author at: Department of Neurology, Sanjay Gandhi Post Graduate Institute of Medical Sciences, Raebareily Road, Lucknow 226014, India.

E-mail address: drukmisra@rediffmail.com (U.K. Misra). rheumatic heart disease, central nervous system (CNS) infection and high prevalence of cerebral venous sinus thrombosis (CVST). In CVST, seizures are reported in $12-46.7 \%$ patients whereas $44.3 \%$ of patients may have early seizures. ${ }^{7-9}$ The patients with sensory motor deficit, cortical vein thrombosis, and supratentorial lesion on CT or MRI are more likely to have seizures compared to those without these features. ${ }^{7,9,10}$ The pathophysiology of seizures in arterial and venous stroke is different. There is no study comparing frequency, spectrum and predictors of seizure in arterial and venous stroke. In the present study, we report the spectrum, predictors and prognosis of patients with seizures in arterial and venous stroke.

\section{Subjects and methods}

In a hospital based observational study, the patients with stroke and CVST during 2010-2015 were included. The study was approved by the Institute Ethics Committee. (PGI/BE/774)

\subsection{Definitions}

Stroke was defined as "rapidly developing clinical signs of focal (or global) disturbance of cerebral function, lasting more than $24 \mathrm{~h}$ 
or leading to death, with no apparent cause other than that of vascular origin". ${ }^{11}$ The diagnosis of stroke was confirmed on CT/ MRI scan. To have a uniform classification, Oxford classification was followed to define the arterial territory of ischemic stroke. ${ }^{12}$ The etiological subtypes of ischemic stroke were classified according to the Trial of ORG 1072 in Acute Stroke Treatment (TOAST) criteria. The ischemic stroke was categorized into small vessel stroke, large vessel stroke, cardioembolic, stroke of undetermined source and stroke of other determined source. ${ }^{13}$ The hemorrhagic stroke was classified as primary ICH as lobar, ganglionic (caudate, thalamic, putaminal), pontine and cerebellar. The size and intrventricular extension of hematoma were noted. ${ }^{14}$ The patients with CVST were defined on the basis of magnetic resonance venography (MRV). The location and extent of thrombosis and number of sinuses involved were noted. Presence of parenchymal lesions and its nature (infarction, hemorrhagic infarction or hemorrhage) were noted.

\subsection{Exclusion}

The patients with trauma, vascular malformation, coagulopathy, malignancy and tumor bleed were excluded. The patients with past history of seizures, febrile convulsion and associated structural lesion other than arterial stroke or CVST were also excluded.

\subsection{Seizure}

The seizures were defined as early seizure if occurred within 14 days of stroke onset, and late seizure if occurred after 14 day. The seizures occurring before the diagnosis of stroke were defined as presenting seizure. The presenting seizure was included in early seizure for comparison between early seizure and late seizures. Early seizure witnessed by doctor or paramedical staff was documented and EEG was done. Late seizure was documented in subsequent follow up of patients. Status epilepticus (SE) was categorized into convulsive and nonconvulsive. Convulsive SE was defined as $5 \mathrm{~min}$ or more of continuous clinical and/or electrographic seizure or recurrent seizure without recovery of consciousness to baseline between the seizures. Nonconvulsive SE was defined as alteration of consciousness lasting for $30 \mathrm{~min}$ or more with epileptiform discharges in EEG with or without suppression of EEG activity by IV benzodiazepine.

\subsection{Evaluation}

Stroke risk factors such as diabetes, hypertension, hyperlipidemia, heart disease, obesity and hyperhomocysteinemia were noted. The patient was considered hypertensive if there was documented history of hypertension, received antihypertensive treatment or blood pressure was above $140 / 90 \mathrm{~mm}$ of $\mathrm{Hg}$ after 2 weeks of stroke or on follow up. ${ }^{15}$ The patients were considered diabetic if they were on antidiabetic treatment or fasting blood sugar was $\geq 126 \mathrm{mg} / \mathrm{dl}$ or $2 \mathrm{~h}$ post prandial blood sugar $\geq 200 \mathrm{mg} / \mathrm{dl}$. The underlying etiology of CVST such as pregnancy, oral contraceptive pills, factor $\mathrm{V}$ Leiden mutation, prothombin gene mutation, hyperhomocysteinemia, antinuclear antibody, antiphospholipid antibody and hematological causes (anemia, paroxysmal nocturnal hematuria, polycythemia, and thrombocytopenia) were noted.

Consciousness was assessed by Glasgow Coma Scale (GCS). Presence of cranial nerve palsy and fundus abnormalities was noted. Focal weakness was categorized as hemiplegia, monoplegia or quadriplegia (as partial or complete weakness). Muscle tone and tendon reflex were graded as increased, normal or decreased. Coordination and sensations were also tested in the patients who could co-operate. Severity of stroke was graded using NIHSS score. Outcome on discharge was defined by modified Rankin Scale $(\mathrm{mRS})$ as good $(\leq 2)$ or poor $(>2)$.

\subsection{Treatment}

The patients were given symptomatic and supportive treatment including management of underlying cause. Seizures were treated with antiepileptic drugs and SE by $0.1 \mathrm{mg} / \mathrm{kg}$ lorazepam IV followed by sodium valproate $20 \mathrm{mg} / \mathrm{kg}$, levetiracetam $30 \mathrm{mg} / \mathrm{kg}$ or phenytoin $10 \mathrm{mg} / \mathrm{kg}$ IV. Raised intracranial pressure (ICP) was treated by mannitol, respiratory failure by mechanical ventilation, fever by cold sponging and paracetamol. Fluid, electrolyte and calories were administered by nasogastric and/or intravenous route. The patients with arterial stroke received management of the risk factors. The patients with CVST were treated with low molecular weight heparin (LMWH) or unfractionated heparin (UFH) for 14 days followed by oral anticoagulant to maintain INR of $2-2.5$.

\section{Results}

Our results are based on 128 patients with CVST and 870 patients with arterial stroke which were admitted during 20102015. Seizures were present in 74 (57.8\%) patients with CVST and 119 (13.7\%) with arterial stroke. In the patients with arterial stroke, 29 patients had $\mathrm{ICH} ; 18(62.1 \%)$ of them had early and 11 (37.9\%) had late seizures. The hematomas were lobar in 18 and ganglionic/ thalamic in 19 patients. In ischemic arterial stroke, 51 (56.7\%) patients had late seizure and 39 (43.3\%) had early seizure, and status epilepticus was present in 24 (26.7\%). Status epilepticus was present in both CVST (24.3\%) and arterial (25.2\%) stroke. Secondary generalized seizures were more common in arterial stroke $(90.8 \%)$ than CVST $(81.1 \%)(p=0.05)$. Early seizures were also more common in CVST (98.6\%) compared to arterial (47.9\% p $=0.001)$, whereas late seizures were more common in arterial $(52.1 \%)$ compared to CVST ( $1.4 \% ; \mathrm{p}=0.001)$. Presenting seizures resulted in SE more commonly in arterial (19.3\%) than CVST (16.2\%).

Table 1

Comparison of demographic and clinical parameters in arterial stroke and cerebral venous sinus thrombosis (CVST) with seizure.

\begin{tabular}{|c|c|c|c|}
\hline Parameters & CVST, $\mathrm{n}=74(\%)$ & Arterial, $\mathrm{n}=119(\%)$ & $P$ value \\
\hline Age (in years) & $31.9 \pm 12.5$ & $54.6 \pm 16.3$ & $<0.001$ \\
\hline Female & $34(45.9)$ & $39(32.8)$ & 0.07 \\
\hline \multicolumn{4}{|l|}{ Seizures- } \\
\hline Early & $73(98.6)$ & 57 (47.9) & \multirow[t]{2}{*}{0.001} \\
\hline Late & $1(1.4)$ & $62(52.1)$ & \\
\hline Status epilepticus & $18(24.3)$ & $30(25.2)$ & 1.00 \\
\hline Focal deficit & 48 (64.9) & $106(89.1)$ & 0.001 \\
\hline Admission GCS (mean \pm SD) & $12.11 \pm 3.50$ & $12.28 \pm 3.044$ & 0.72 \\
\hline Mechanical ventilation & $9(12.2)$ & $6(5)$ & 0.09 \\
\hline \multicolumn{4}{|l|}{ Types of lesion } \\
\hline Ischemic & $13(17.6)$ & $90(75.6)$ & \multirow[t]{2}{*}{0.001} \\
\hline Hemorrhage & $49(66.2)$ & $29(24.4)$ & \\
\hline \multicolumn{4}{|l|}{3 month mRS } \\
\hline Good $(\leq 2)$ & $58(78.4)$ & $53(44.5)$ & \multirow[t]{2}{*}{0.001} \\
\hline Poor $(>2)$ & $16(21.6)$ & $66(55.5)$ & \\
\hline Death & $10(13.5)$ & $3(2.5)$ & 0.006 \\
\hline
\end{tabular}

GCS = Glasgow Coma Scale, mRS = Modified Rankin Scale. 
Nonconvulsive SE was insignificantly more common in arterial stroke $(p=0.23)$ (Table 1$)$. The mean follow up of venous stroke patients with seizure was $26.41 \pm 12.99$ month and 4 patients lost from follow up, while in arterial stroke patients, the mean follow up was $19.40 \pm 10.46$ month and 28 (23.5\%) patients lost from follow up.

\subsection{Predictors of seizures}

Comparing the arterial stroke patients with and without seizure, the type of stroke (hemorrhagic vs. ischemic; $\mathrm{p}=0.001$ ), arterial territory of ischemic stroke (anterior vs. posterior circulation; $p=0.008)$, admission GCS score $(p=0.004)$, admission NIHSS score $(p=0.002)$, outcome on discharge $(p=0.005)$ and age $(p=0.01)$ were the predictors of seizure on univariate analysis. On multivariate analysis, anterior territory of ischemic stroke was independent predictor of seizure (OR 3.95, 95\% CI 1.51-10.32, $\mathrm{p}=0.005$ ).

Comparing the CVST patients with and without seizure, focal deficit $(p=0.004)$, parenchymal lesion $(p=0.001)$, frontal lobe involvement $(p=0.003)$ and papilledema $(p=0.01)$ were the predictors of seizure on univariate analysis. On multivariate analysis presence of parenchymal lesion was independent predictor of seizure (OR 2.61, 95\% CI 1.04-6.55, p=0.04) (Table 2).

\subsection{Outcome}

There were more deaths in CVST compared to arterial stroke ( $13.5 \%$ vs. $2.5 \% ; \mathrm{p}=0.006$ ). The functional outcome however was better in the CVST patients with seizure compared to arterial stroke (73\% vs. 35.3\%, p=0.001) (Fig. 1).

On comparing the CVST patients with seizure, with good (mRS up to 2 ) and poor (mRS 3-6) outcome at 3 month follow up; GCS score on admission $(p=0.001), M V(p=0.001)$, focal weakness $(p=0.03)$, bilateral lesions $(p=0.03)$, and involvement of both superficial and deep sinus $(p=0.03)$ were the predictors of poor outcome on univariate analysis. Using binary logistic regression, involvement of both superficial and deep sinuses (OR 63.47, CI 1.36-2946.69, p = 0.03), lower admission GCS (OR 1.92, 95\% CI 1.252.96, $\mathrm{p}=0.003$ ) and use of MV (OR 39.85, 95\% CI 2.95-537.33, $\mathrm{p}=0.005$ ) were significant predictors of poor outcome (Table 3 ).

On comparing the arterial patients with good (mRS up to 2 ) and poor (mRS 3-6) outcome on discharge; admission GCS score $(p=0.002)$, NIHSS score on admission $(p=0.001)$ and duration of hospitalization $(\mathrm{p}=0.002)$ were the predictors of outcome on univariate analysis. Using binary logistic regression, GCS score (OR 1.37, CI 1.02-1.84, $\mathrm{p}=0.03$ ) and NIHSS on admission (OR 1.42, 95\% CI 1.19-1.70, $\mathrm{p}=0.001$ ) and duration of hospitalization (OR 1.15, $95 \%$ CI 1.02-1.29, $\mathrm{p}=0.023$ ) were significant predictors of outcome (Table 4).

\section{Discussion}

In the present study, the seizures were more common in CVST (57.8\%) than in arterial stroke (13.7\%). CVST related seizures were more intractable and resulted in higher mortality but the survivors had better outcome than arterial stroke. The arterial strokes resulted in more frequent late seizures. The predictor of seizure in CVST was parenchymal involvement, and in arterial stroke was carotid territory infarction. This is the first study comparing the frequency and spectrum of seizure in arterial and venous stroke and its effect on outcome. The frequency of seizure in the present study in arterial stroke is in agreement with the reported frequency of post stroke seizures which is up to $11.5 \%$ and in CVST up to $43.5 \%{ }^{7}$ Slightly higher frequency of seizures in CVST in the present study may be due to difference in patient population. In ischemic stroke, severity of neurological deficit, severity of persistent disability after stroke, involvement of multiple sites, large lesion, cortical damage or hippocampal involvement predicted development of post stroke seizure. ${ }^{6}$ In our study, 29 patients $(24.4 \%)$ with ICH had seizures; early seizure in $62.1 \%$ and late seizure in $37.9 \%$ patients. Similar results have been found in other studies as well. In a study on 123 patients with ICH followed up for a period of 4.6 years, seizure occurred in $25 \%$ of patients. In

Table 2

Comparison of CVST (cerebral venous sinus thrombosis) patients with and without seizure.

\begin{tabular}{|c|c|c|c|}
\hline Parameters & CVST with seizure, $\mathrm{n}=74(\%)$ & CVST without seizure, $\mathrm{n}=54(\%)$ & $P$ value \\
\hline Age (mean $\pm \mathrm{SD}$ ) & $31.86 \pm 12.50$ & $33.76 \pm 16.12$ & 0.47 \\
\hline Sex (Female) & $34(45.9)$ & $32(59.3)$ & 0.16 \\
\hline GCS score at admission (mean \pm SD) & $12.11 \pm 3.50$ & $13.09 \pm 3.03$ & 0.09 \\
\hline Ventilation & $9(12.2)$ & $4(7.4)$ & 0.56 \\
\hline Duration of hospitalization (mean $\pm \mathrm{SD}$ ) & $17.89 \pm 11.77$ & $17.41 \pm 8.95$ & 0.80 \\
\hline Focal deficit & $48(64.9)$ & $21(38.9)$ & 0.004 \\
\hline Papilloedema & $15(20.3)$ & $23(42.6)$ & 0.01 \\
\hline Parenchymal lesion & $63(85.1)$ & $31(57.4)$ & 0.001 \\
\hline Frontal lobe & $29(39.2)$ & $8(14.8)$ & 0.003 \\
\hline \multicolumn{4}{|l|}{ Type of lesion } \\
\hline Ischemic & $13(17.6)$ & $11(20.4)$ & 0.14 \\
\hline Hemorrhagic & $49(66.2)$ & $20(37)$ & \\
\hline \multicolumn{4}{|l|}{3 month mRS } \\
\hline Good $(\leq 2)$ & $58(78.4)$ & $45(83.3)$ & 0.51 \\
\hline Poor $(>2)$ & $16(21.6)$ & $9(16.7)$ & \\
\hline Death & $10(13.5)$ & $6(11.1)$ & 0.80 \\
\hline
\end{tabular}

GCS = Glasgow Coma Scale, mRS = Modified Rankin Scale. 
Good outcome at discharge

Poor outcome at discharge

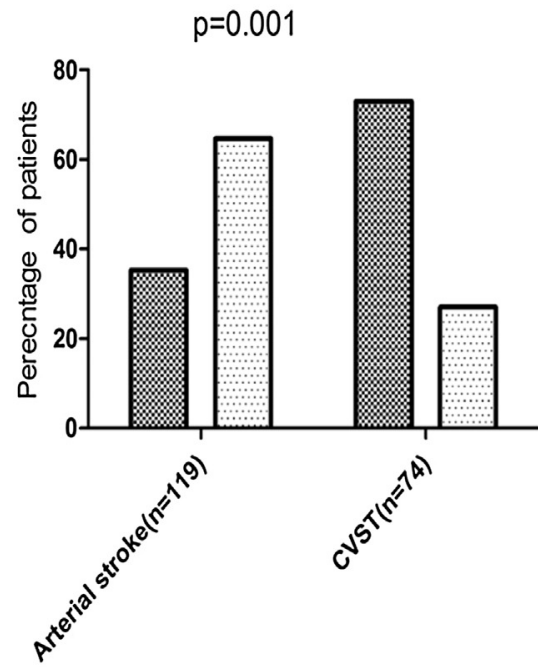

Good outcome at 3 month

Poor outcome at 3 month

$p=0.001$
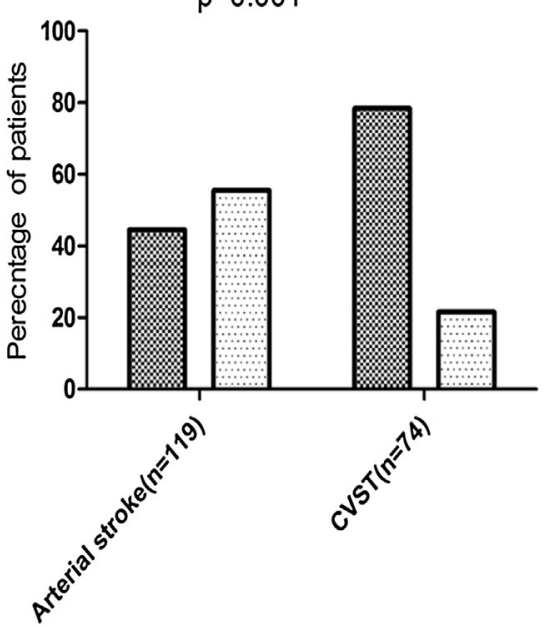

Fig. 1. Bar diagram showing outcome ( $\mathrm{mRS}$ grade-Good $\leq 2$, Poor $>2$ ) at discharge and three month in patients of CVST and arterial stroke with seizure.

Table 3

Comparison of outcome of CVST (cerebral venous sinus thrombosis) patients with seizure at 3 month.

\begin{tabular}{|c|c|c|c|}
\hline Parameters & $\begin{array}{l}\text { CVST, }(\mathrm{mRS}>2) \\
\mathrm{N}=16(\%)\end{array}$ & $\begin{array}{l}\text { CVST }(m R S \leq 2) \\
\mathrm{N}=58(\%)\end{array}$ & $P$ value \\
\hline Age $($ mean $\pm \mathrm{SD})$ & $35.31 \pm 15.37$ & $30.91 \pm 11.56$ & 0.30 \\
\hline Sex (Female) & $7(43.8)$ & $27(46.6)$ & 0.84 \\
\hline Altered sensorium & $13(81.3 \%)$ & $33(56.9)$ & 0.075 \\
\hline Admission GCS (mean \pm SD) & $8.75 \pm 4.10$ & $13.03 \pm 2.68$ & 0.001 \\
\hline Ventilation & $8(50)$ & $1(1.7)$ & 0.001 \\
\hline Duration of hospitalization (mean $\pm S \mathrm{SD}$ ) & $16.18 \pm 17.75$ & $18.41 \pm 9.44$ & 0.63 \\
\hline Focal deficit & $14(87.5)$ & $34(58.6)$ & 0.03 \\
\hline Papilloedema & $4(25)$ & $11(19)$ & 0.60 \\
\hline Parenchymal lesion & $15(93.8)$ & $48(82.8)$ & 0.27 \\
\hline \multicolumn{4}{|l|}{ Type of lesion } \\
\hline Ischemic & $4(25)$ & $9(15.5)$ & 0.53 \\
\hline Hemorrhagic & $11(68.8)$ & $38(65.5)$ & \\
\hline Bilateral lesions & $8(50)$ & $13(22.4)$ & 0.03 \\
\hline Total number of sinus involved (mean $\pm S D$ ) & $2.06 \pm 1.28$ & $1.98 \pm 1.23$ & 0.82 \\
\hline Superficial sinus & $12(75)$ & $51(87.9)$ & 0.19 \\
\hline Deep sinus & 0 & $3(5.2)$ & 0.35 \\
\hline Both superficial and deep sinus & $4(25.0)$ & $4(6.9)$ & 0.03 \\
\hline
\end{tabular}

the more recent studies, the seizure frequency is higher in ICH compared to the earlier, because small lobar hemorrhages are more likely to produce seizure which can be detected by CT scan. ${ }^{16}$ The products of blood metabolites such as hemosiderin and iron may cause seizure by local cerebral irritation. ${ }^{17}$ The epileptogenic lobar ICH may involve the gray-white matter interface, creating a condition similar to the surgical isolation of cortex resulting in its sustained paroxysmal activity. Direct irritation of the cortex is also a possible mechanism of post seizures in $\mathrm{ICH}^{18}$ The higher frequency of seizures in hemorrhagic infarction both in CVST and arterial strokes have been reported. ${ }^{9}$

In prospective studies, seizure was not related to severity of stroke. ${ }^{19,20}$ In a Chinese study, cortical location of stroke was associated with 3.8 times higher risk of seizure. ${ }^{21}$

In our study, SE is the predictor of poor outcome on discharge in arterial stroke patients but not CVST. Development of epilepsy and the independent effect of SE on mortality is controversial. ${ }^{22-24}$ In our study, CVST had higher mortality (13.5\%) than arterial stroke (2.5\%). Severity of stroke is a predictor of outcome but the effect of seizure on outcome of stroke is uncertain. In a prospective cohort study, $48 \mathrm{~h}$ mortality was found to be higher in the patients with early seizures (38.4\%) compared to those without early seizure $(7.4 \% ; \mathrm{p}<0.01) .{ }^{25}$ In this study the effect of location and stroke severity were not adjusted. Moreover the effect on mortality rates was not significant at the time of discharge or follow up at 27 months. A large hospital based study reported that early seizures were associated with increase in hospital mortality in atherothrombotic infarction. ${ }^{26}$ However after accounting for stroke severity, population based studies have not found association between early post stroke seizure and mortality. ${ }^{20,27}$ Higher death in CVST and worse outcome in the survivors of ischemic stroke may be related to underlying pathophysiology of arterial and venous stroke.

The mechanism of seizures in stoke depends on the timing. The early seizures are attributable to biochemical alterations leading to electrical instability. ${ }^{28}$ Acute ischemia results in increased extracellular concentration of glutamate which results in secondary neuronal injury. Epileptiform neuronal discharges can occur in 
Table 4

Comparison of outcome in the patients of arterial stroke with seizure at discharge.

\begin{tabular}{|c|c|c|c|}
\hline Parameters & $\begin{array}{l}\text { Arterial stroke }(\mathrm{mRS} \leq 2) \\
\mathrm{N}=42(\%)\end{array}$ & $\begin{array}{l}\text { Arterial stroke, }(\mathrm{mRS}>2) \\
\mathrm{N}=77(\%)\end{array}$ & $P$ value \\
\hline Age (mean $\pm \mathrm{SD}$ ) & $51.55 \pm 15.86$ & $56.29 \pm 16.33$ & 0.12 \\
\hline Sex (Female) & $18(42.9)$ & $21(27.3)$ & 0.08 \\
\hline Hospitalization duration (mean \pm SD) & $7.90 \pm 4.23$ & $18.29 \pm 17.93$ & 0.002 \\
\hline NIHSS score admission (mean \pm SD) & $6.95 \pm 4.42$ & $14.41 \pm 6.92$ & 0.001 \\
\hline GCS score at admission (mean $\pm \mathrm{SD}$ ) & $13.37 \pm 2.25$ & $11.70 \pm 3.25$ & 0.002 \\
\hline Ventilation & $2(4.8)$ & $4(5.2)$ & 0.91 \\
\hline Focal deficit & $36(85.7)$ & $70(90.9)$ & 0.38 \\
\hline Death & 0 & $3(3.9)$ & 0.19 \\
\hline \multicolumn{4}{|l|}{ Type of stroke } \\
\hline Ischemic & $33(78.6)$ & $57(74)$ & 0.66 \\
\hline Hemorrhagic & $9(21.4)$ & $20(26)$ & \\
\hline \multicolumn{4}{|l|}{ Type of ischemic stroke } \\
\hline Anterior circulation & $26(61.9)$ & $49(63.6)$ & 0.25 \\
\hline Posterior circulation & $8(19)$ & $8(10.4)$ & \\
\hline
\end{tabular}

surviving neurons exposed to high levels of glutamate. ${ }^{29}$ Late seizures are attributable to gliosis and meningocerebral cicatrix. ${ }^{30}$ Changes in membrane properties, selective neuronal loss and collateral sprouting may result in hyperexcitabilty and seizures. ${ }^{31}$ The pathophysiological mechanisms in venous and arterial stroke also differ. CVST is less acute, Occlusion of venous sinuses results in stagnation of blood, hypoxia, diapediasis of RBC, edema, raised intracranial pressure and venous infarction. Oxidative stress, apoptosis, inflammation, necrosis and endoplasmic reticulum stress have been reported in CVST which manifest at a slower rate than arterial stroke. ${ }^{32}$ Following therapy in CVST or even spontaneously, there may be thrombolysis or recanalization of venous sinuses which may account for the lower incidence of late seizures in CVST and fewer sequelae compared to arterial stroke. The arterial stroke on the other hand is more acute and results in persistent changes, including necrosis, apoptosis and infarction especially involving epileptogenic area of cortex account for higher frequency of late post stroke seizure in arterial stroke.

Ours is the first study comparing the frequency, spectrum and outcome of seizures in arterial and venous stroke. This study is however limited by retrospective design. This hospital based study has a referral bias of a tertiary care hospital. In which the patients included are more sick and do not represent the patients in the community.

It can be concluded that CVST results in more frequent and early seizures whereas in arterial stroke, late seizures are common. Though CVST had higher mortality but their survivors have better outcome.

\section{Funding support}

None.

\section{Conflict of interest}

The authors have none to declare.

\section{Ethical approval}

This study was approved by Institutional Ethics Committee, SGPGIMS, Lucknow INDIA.

\section{Acknowledgements}

We thank Mr. Shakti Kumar for secretarial help.

\section{References}

1. Lühdorf K, Jensen LK, Plesner AM. Etiology of seizures in the elderly. Epilepsia. 1986:27:458-463.

2. Olsen TS. Post-stroke epilepsy. Curr Atheroscler Rep. 2001;3:340-344.

3. Burn J, Dennis M, Bamford J, Sandercock P, Wade D, Warlow C. Epileptic seizures after a first stroke: the Oxfordshire Community Stroke Project. BMJ. 1997;315:1582-1587.

4. Hauser WA, Annegers JF, Kurland LT. Incidence of epilepsy and unprovoked seizures in Rochester, Minnesota: 1935-1984. Epilepsia. 1993;34:453-468.

5. Zou S, Wu X, Zhu B, Yu J, Yang B, Shi J. The pooled incidence of post-stroke seizure in 102008 patients. Top Stroke Rehabil. 2015;22:460-467.

6. Browne TR, Holmes GL. Epilepsy. N Engl J Med. 2001;344:1145-1151.

7. Ferro JM, Correia M, Rosas MJ, Pinto AN, Neves G. Cerebral venous thrombosis portuguese collaborative study group [Venoport]. Seizures in cerebral vein and dural sinus thrombosis. Cerebrovasc Dis. 2003;15:78-83.

8. Masuhr F, Busch M, Amberger N, et al. Risk and predictors of early epileptic seizures in acute cerebral venous and sinus thrombosis. Eur J Neurol. 2006;13:852-856.

9. Kalita J, Chandra S, Misra UK. Significance of seizure in cerebral venous sinus thrombosis. Seizure. 2012;21(October):639-642.

10. Preter M, Tzourio C, Ameri A, Bousser MG. Long-term prognosis in cerebral venous thrombosis. Follow-up of 77 patients. Stroke. 1996;27:243-246.

11. Aho K, Harmsen P, Hatano S, Marquardsen J, Smirnov VE, Strasser T. Cerebrovascular disease in the community: results of a WHO collaborative study. Bull World Health Organ. 1980;58:113-130.

12. Bamford J, Sandercock P, Dennis M, Burn J, Warlow C. Classification and natural history of clinically identifiable subtypes of cerebral infarction. Lancet. 1991;337:1521-1526.

13. Adams Jr. HPJr., Bendixen BH, Kappelle LJ, et al. Classification of subtype of acute ischemic stroke. Definitions for use in a multicenter clinical trial. TOAST. Trial of Org 10172 in acute stroke treatment. Stroke. 1993;24(1):35-41.

14. Kalita J, Misra UK, Vajpeyee A, Phadke RV, Handique A, Salwani V. Brain herniations in patients with intracerebral hemorrhage. Acta Neurol Scand. 2009;119:254-260.

15. National High Blood Pressure Education Program Coordinating Committee. The seventh report of the joint national committee on prevention, detection, 
evaluation, and treatment of high blood pressure: the JNC 7 report. JAMA. 2003;289:2560-2571.

16. Faught E, Peters D, Bartolucci A, Moore L, Miller PC. Seizures after primary intracerebral hemorrhage. Neurology. 1989;39:1089-1093.

17. Küçükkaya B, Aker R, Yüksel M, Onat F, Yalçin AS. Low dose MK-801 protects against iron-induced oxidative changes in a rat model of focal epilepsy. Brain Res. 1998;30(788):133-136.

18. Echlin FA, Arnett V, Zoll J. Paroxysmal high voltage discharges from isolated and partially isolated human and animal cerebral cortex. Electroencephalogr Clin Neurophysiol. 1952;4:147-164.

19. Bladin CF, Alexandrov AV, Bellavance A, et al. Seizures after stroke: prospective multicenter study. Arch Neurol. 2000;57:1617-1622.

20. Labovitz DL, Hauser WA, Sacco RL. Prevalence and predictors of early seizure and status epilepticus after first stroke. Neurology. 2001 24;57:200-206.

21. Cheung CM, Tsoi TH, Au-Yeung M, Tang AS. Epileptic seizure after stroke in Chinese patients. J Neurol. 2003;250:839-843.

22. Rumbach L, Sablot D, Berger E, Tatu L, Vuillier F, Moulin T. Status epilepticus in stroke: report on a hospital-based stroke cohort Neurology 2000:54:350-354.

23. Velioğlu SK, Ozmenoğlu M, Boz C, Alioğlu Z. Status epilepticus after stroke Stroke. 2001;32:1169-1172.

24. Camilo O, Goldstein LB. Seizures and epilepsy after ischemic stroke. Stroke. 2004;35:1769-1775.
25. Shinton RA, Gill JS, Melnick SC, Gupta AK, Beevers DG. The frequency, characteristics and prognosis of epileptic seizures at the onset of stroke. $J$ Neurol Neurosurg Psychiatry. 1988;51:273-276.

26. Arboix A, Comes E, García-Eroles L, Massons JB, Oliveres M, Balcells M. Prognostic value of very early seizures for in-hospital mortality in atherothrombotic infarction. Eur Neurol. 2003;50:78-84.

27. Reith J, Jørgensen HS, Nakayama H, Raaschou HO, Olsen TS. Seizures in acute stroke: predictors and prognostic significance. The Copenhagen stroke study. Stroke. 1997;28:1585-1589.

28. Luhmann HJ. Ischemia and lesion induced imbalances in cortical function. Prog Neurobiol. 1996:48:131-166.

29. Sun DA, Sombati S, DeLorenzo RJ. Glutamate injury-induced epileptogenesis in hippocampal neurons: an in vitro model of stroke-induced epilepsy. Stroke. 2001;32:2344-2350.

30. Jennett B. Posttraumatic epilepsy. Adv Neurol. 1979;22:137-147.

31. Luhmann HJ, Mudrick-Donnon LA, Mittmann T, Heinemann U. Ischaemiainduced long-term hyperexcitability in rat neocortex. Eur J Neurosci. 1995; 7:180-191.

32. Tiwari HS, Tripathi AK, Mishra DP, Kalita J, Misra UK. A study of ER stress in rat model of cerebral venous sinus thrombosis. Neurosci Lett. 2015;589:121-125. 